\title{
3. Unit Costs and their Calculation
}

A unit cost is the cost of educating one pupil for one year. It is composed of both capital and recurrent components:

Capital costs arise from expenditure on long-lasting items, e.g. land, buildings, equipment, furniture and library books.

Recurrent costs arise from day-to-day needs. In education, the greatest recurrent costs are teachers' salaries. Other ones are electricity, gas, water, exercise books, chalk, maintenance of buildings, and maintenance of equipment.

Part II of this book shows that both capital and recurrent unit costs are usually higher in practical than in other subjects. Practical subjects require more expensive buildings and equipment, and are usually taught to smaller classes. In addition, teachers of practical subjects often attract higher salaries than others, and they often have to be supported by technicians and other staff.

\section{(a) Unit Capital Costs}

Unit capital costs are calculated by dividing the total capital costs of education in one year by the number of pupils. Because buildings are long-lasting and are not 'used up' within a year, only a percentage of their construction cost should be taken. This calculation is called 'amortisation'.

The method of calculating unit capital costs may best be explained by an example:

Assume a typical secondary school with a diversified curriculum. It wants to introduce metalwork, but has to construct the workshops. The school has 875 students, but only 674 of them will take metalwork. 
(i) Total Costs:

(a) Size of each workshop

$250 \mathrm{sq}$. metres

(b) Construction cost $\$ 482$ per sq. metre

(c) Construction cost of one workshop $\$ 120,500$

(d) Cost of equipment $\$ 22,600$

(e) Cost of furniture

$\$ 3,100$

(f) Total cost (c) $+(d)+(e)$

(g) Number of workshops required $\$ 146,200$

(h) Total cost of 2 workshops

2

$\$ 292,400$

(ii) Amortisation:

(a) Average useful life of buildings Cost per year

25 years

$\$ 4,820$

(b) Average useful life of equipment

10 years Cost per year

$\$ 2,260$

(c) Average useful life of furniture

Cost per year

15 years

$\$ 207$

(d) Total cost per year

$\$ 7,287$

(iii) Unit Capital Cost:

Total cost per year divided by the number of students

$$
\$ 7,287 \div 674
$$

$\$ 10.81$

\section{(b) Unit Recurrent Costs}

The method for calculating unit recurrent costs may be shown by continuing the above example:

Assume that the school has: 5 grades (Grades 7-11)

5 classes in each grade, and thus 25 classes altogether.

Each class has 33 pupils. In Grades 7, 8 and 9, all pupils have to take 2 periods of metalwork each week. Students in Grades 10 and 11 specialise; some do not take any metalwork, some take a little, and some take a lot. The different streams in Grades 10 and 11 have to be taught separately. 
(i) Number of Periods and Pupils:

Grades 7, 8 \& 9:

(each 5 classes $\times 33$ pupils)

(each 5 classes $\times 2$ periods)

Periods Pupils

495

30

Grade 10: Arts Stream

Science Stream

Automotor Stream

$\begin{array}{cc}- & - \\ 7 & 33 \\ - & - \\ 4 & 28\end{array}$

Building/Construction Stream

Grade 11: Arts Stream

Science Stream

Automotor Stream

$\begin{array}{cc}- & - \\ 7 & 25 \\ - & 33 \\ 4 & 29\end{array}$

Commerce Stream

Building/Construction Stream

TOTALS: $\quad 55 \quad 674$

(ii) Teacher Costs:

Assume: * normal load is 28 teaching periods per week. $55 \div$ $28=1.96$. Rounding up, this becomes 2 teachers.

* the total costs for each teacher for one year (i.e. salary + pension + bonuses + travel etc.) are $\$ 11,250$.

$\$ 11,250 \times 2=\$ 22,500$

(iii) Other Salary Costs:

Assume: * 2 technicians are required. Total annual costs for each are \$8,500. For both of them, therefore, the total cost is $\$ 17,000$.

* extra costs of cleaners, night watchmen and administrators amount to $\$ 4,500$.

(iv) Costs of Materials:

Assume raw materials, electricity, gas, etc. cost $\$ 10$ per pupil. $\$ 10 \times 674=\$ 6,740$ 
(v) Total Costs:

Teachers

$\$ 22,500$

Technicians

17,000

Cleaners etc.

4,500

Materials

6,740

TOTAL: $\$ 50,740$

(vi) Unit Costs:

Total cost per year divided by the number of students

$$
\$ 50,740 \div 674=\$ 75.28
$$

\section{(c) Assumptions in Cost Analysis}

The assumptions underlying a cost calculation can make a big difference to the result, and should be examined very carefully. It is particularly important to check that reasonable estimates have been made for salaries, materials and the life of buildings and equipment.

In addition, three further points should be made:

* Average Costs or Marginal Costs? Note that item (iii) in this calculation shows only the extra costs of cleaners, night watchmen, administrators, etc.. It assumes that people are already being employed for the school, and thus calculates only the extra needs for the workshops. This is called the marginal cost.

However, planners often prefer to calculate the average cost, i.e. the total cost of all cleaners, night watchmen and administrators divided by the total number of pupils. The figure may be quite different. If people had to be specially appointed because of the construction of the workshops, marginal costs would probably be higher than average costs. But if people were already employed and were just given extra duties, marginal costs would be lower than average costs.

* Only the Metalwork Students or All the Students? The unit cost was based only on the 674 students who will actually take metalwork, not the 875 students in the school as a whole. If the authorities had decided to divide by the total number of students, they would have reached a lower figure.

* Current Enrolments or Future Enrolments? The figure of 674 pupils who will take metalwork was only an estimate based on current enrolments and pupil choices. Future changes in the 
number of pupils wishing to take metalwork could considerably change the unit cost.

\section{(d) Practical Subjects Compared with Other Subjects}

As mentioned above, unit costs in practical subjects are usually higher than in other subjects. Four reasons for this are: (i) practical subjects require more expensive buildings and equipment, (ii) they are usually taught in smaller classes, (iii) teachers of technical subjects often attract higher salaries than other teachers, and (iv) teachers often have to be supported by technicians and other personnel.

More explanation of these points is given in Part II of this book. Meanwhile, Figure 3.1 shows a possible range of unit costs in different subjects. Unit costs are much higher in practical subjects than in English, social studies, religion, etc.. And Table 3.1 shows comparative capital costs of different practical subjects in a typical secondary school.

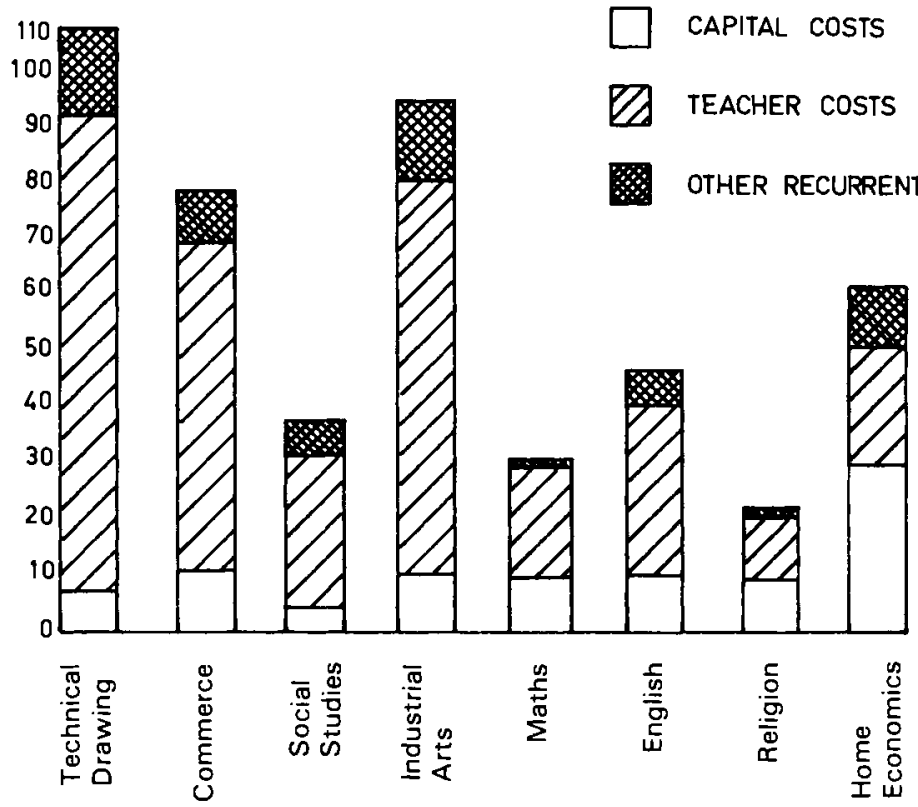

Figure 3.1: Unit Costs, by Subject 
Table 3.1: Capital Costs of Workshop and Classroom Places at New Wotton School, Barbados, 1986 (US\$)

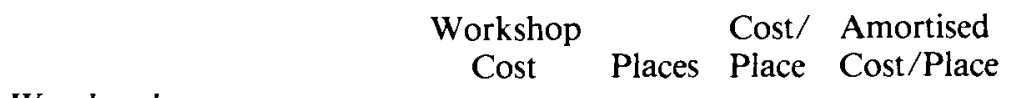

Woodwork

$\begin{array}{lrrrr}\text { Construction (100 sq.m.) } & 84,900 & 20 & 4,246 & 467 \\ \text { Furniture } & 6,540 & & 327 & 43 \\ \text { Equipment } & 20,000 & & 1,000 & 160 \\ \quad \text { Total } & 111,440 & & 5,573 & 670\end{array}$

Metalwork

$\begin{array}{lrrrr}\text { Construction (100 sq.m.) } & 84,900 & 20 & 4,246 & 467 \\ \text { Furniture } & 6,540 & & 327 & 43 \\ \text { Equipment } & 30,000 & & 1,500 & 240 \\ \quad \text { Total } & 121,440 & & 6,073 & 750\end{array}$

Basic Auto

$\begin{array}{lrrrr}\text { Construction (120 sq.m.) } & 101,900 & 20 & 5,095 & 560 \\ \text { Furniture } & 7,840 & & 392 & 51 \\ \text { Equipment } & 25,000 & & 1,250 & 199 \\ \quad \text { Total } & 134,740 & & 6,737 & 810\end{array}$

Electrics/Electronics

$\begin{array}{lrrrr}\text { Construction (80 sq.m.) } & 67,900 & 20 & 3,395 & 374 \\ \text { Furniture } & 5,230 & & 262 & 34 \\ \text { Equipment } & 15,000 & & 750 & 120 \\ \quad \text { Total } & 88,130 & & 4,407 & 528\end{array}$

Technical Drawing

Construction (90 sq.m.) $\quad 76,400 \quad 30 \quad 2,547 \quad 280$

Furniture

5,880

$196 \quad 26$

Equipment

9,000

$300 \quad 55$

Total

91,280

$3,043 \quad 361$

Science

$\begin{array}{lrrrr}\text { Construction (90 sq.m.) } & 76,400 & 30 & 2,547 & 280 \\ \text { Furniture } & 5,880 & & 196 & 26 \\ \text { Equipment } & 13,500 & & 450 & 72 \\ \quad \text { Total } & 95,780 & & 3,193 & 378\end{array}$

Classroom Subjects

$\begin{array}{lrrrr}\text { Construction (54 sq.m.) } & 45,900 & 30 & 1,530 & 168 \\ \text { Furniture } & 3,530 & & 118 & 17 \\ \quad \text { Total } & 49,430 & & 1,648 & 185\end{array}$


The figures in Table 3.1 may be used to calculate the cost of replacing one student-hour of ordinary academic classroom teaching by one student-hour of vocational teaching. The following assumptions are made:

- students spend seven hours per day in school;

- class size for ordinary lessons is 30 ;

- class size for workshops and laboratories is 15 ;

- teachers are fully utilised.

The conversion of one hour per day of classroom teaching into one hour of practical teaching requires one additional teacher for oneseventh of the day (because two practical teachers are required for two groups of 15 students instead of one classroom teacher). The marginal capital and teacher costs for each type of workshop and for science laboratory work are given in Table 3.2. The marginal costs for practical subjects (excluding science) average at US\$148. This represents an increase of about $10-11 \%$ on the total unit cost for secondary education $(\$ 1,439)$.

Table 3.2: The Cost of Vocationalising Education in New Wotton School, Barbados, 1986 (US\$)

Amortised Amortised Classroom Marginal Instructor Total Cost $/$ Place Cost $\div 7$ Cost Cap. Cost Cost Cost

$\begin{array}{lrrrrrr}\text { Woodwork } & 670 & 96 & 26 & 70 & 85 & 155 \\ \text { Metalwork } & 750 & 107 & 26 & 81 & 85 & 166 \\ \text { Basic Auto } & 810 & 116 & 26 & 90 & 85 & 175 \\ \text { Electricity } & 528 & 75 & 26 & 49 & 85 & 134 \\ \text { Tech Drawing } & 361 & 52 & 26 & 26 & 85 & 111 \\ \text { Science Lab } & 378 & 54 & 26 & 28 & 85 & 113\end{array}$

\section{(e) Computers for Cost Analysis}

Most costs can be effectively analysed with a simple calculator. However, planners who want more complex and detailed analysis should use a computer. A simple programme called the 'Economics of Curricular Choice' is readily available. It can be used either on an IBM PC (using the Lotus 1-2-3 package) or on a Macintosh (using the Excel 
package). The programme may be obtained from:

The Economic Development Institute, The World Bank, 1818 H Street, N.W., Washington DC 20433, USA. 